\title{
Global Surrogacy, Exploitation, Human Rights and International Private Law: A Pragmatic Stance and Policy Recommendations
}

\author{
Nicole F. Bromfield • Karen Smith Rotabi
}

Published online: 1 July 2014

(C) Springer International Publishing 2014

\begin{abstract}
The number of global surrogacy arrangements increased exponentially over the last decade, and the rise in the practice has led to concerns over issues such as social justice, exploitation, and human rights abuses. Currently, there are no international regulations or guidelines regarding global surrogacy arrangements, and in some countries where the practice is prevalent, i.e., India, there is limited national regulation or oversight. Global surrogacy is a complex issue that includes questions related to morality, parentage, the natural motherinfant bond, and the complexities of inequalities in a globalized world that interface with a multi-million dollar industry. The purpose of the paper is to present global surrogacy dynamics written in a manner to help the reader understand this complex phenomenon, including a discussion of the associated problems and ethical dilemmas. The USA and India, two contrasting global surrogacy destination countries, are presented as cases, and some unique matters related to surrogacy in each country are emphasized to highlight the issues. Human rights instruments and international private law are discussed to frame global surrogacy regulation including the rights of the child and the rights of women. The analysis is concluded with pragmatic policy recommendations oriented to some of the practices necessary to regulate global surrogacy arrangements in a fair and consistent manner, while maintaining that ultimately the voices of all involved in global surrogacy contracts, and most especially the surrogates themselves, need to be included in further discussions of the issue.
\end{abstract}

Keywords Globalsurrogacy · International surrogacy · Hague Convention $\cdot$ Human rights $\cdot$ International private law

N. F. Bromfield $(\bowtie) \cdot$ K. S. Rotabi

United Arab Emirates University, P.O. Box 17771, Al Ain, United

Arab Emirates

e-mail: n.bromfield@hotmail.com

\section{Introduction}

As the globalization of reproductive technologies such as in vitro fertilization (IVF) has continued to rise, global surrogacy arrangements are becoming increasingly common (Crozier 2010; Hochschild 2009; Rimm 2009; Stark 2012). As such, interested international players have become progressively concerned about the well-being of all parties involved in contemporary surrogacy arrangements; issues related to surrogate and child welfare, potential exploitation of surrogates, baby-selling, commodification of women, the invasion of the marketplace into the sacred family realm, and questions regarding parentage and citizenship are among the concerns (Berend 2012; Damelio and Sorensen 2008; Gugucheva 2010; Pande 2010b). Global surrogacy arrangements are complicated, involving people from often uneven and vastly different backgrounds in a highly intimate yet commercial relationship, in which a child is created. There also may be other players involved including egg donors and/or sperm donors (Hague Conference on International Private Law 2012; Rimm 2009). Complicating matters further, surrogacy is banned in much of Europe and is highly restricted in countries such as Canada, Australia, New Zealand, and the UK (Hochschild 2009; Rimm 2009); another dimension of complexity is added when those seeking global surrogacy arrangements are from nations in which surrogacy is either banned or highly regulated, mostly due to citizenship issues for the child (Hague Conference on International Private Law 2012). To date, there are no international regulations which directly address global surrogacy, although the rate of these arrangements has risen exponentially in the last decade, with surrogacy becoming a multi-million dollar business in India since commercial surrogacy arrangements were legalized in 2002 (Carney 2010; Hochschild 2009). This is problematic 
because people have been caught between various nations' regulations, while lack of international regulation can encourage exploitive situations (Rimm 2009).

In this paper, global surrogacy dynamics will be presented, written in a manner to help the reader understand this complex phenomenon, including a discussion of the associated problems and ethical dilemmas. The USA and India are presented, as two contrasting case examples, with a focus on gestational surrogacy in each country to highlight the issues, while recognizing the markedly different cultural and social contexts between the two nations. Human rights instruments and international private law are used to frame global surrogacy regulation and the analysis is concluded with pragmatic policy recommendations oriented to some of the practices necessary for the fair execution of global surrogacy arrangements.

\section{Understanding Surrogacy Arrangements}

A surrogacy arrangement is when a woman becomes pregnant and delivers an infant for a commissioning parent or parents, who are unable to carry a pregnancy; these arrangements are also known as contract pregnancies. A gestational surrogacy arrangement is one where the surrogate achieves pregnancy through artificial reproduction technologies (ART) in the form of in vitro fertilization (IVF); embryos are created with gametes provided by the commissioning parent/s and transferred to the uterus of the surrogate in order to achieve a pregnancy and ultimately deliver a healthy infant.

The vast majority of contemporary surrogacy arrangements are gestational surrogacy arrangements, where the surrogate is not genetically related to the infant that she gestates (Rimm 2009; Stark 2012). These arrangements are also known as IVF surrogacy arrangements, since IVF is used to achieve a pregnancy. In gestational surrogacy arrangements both commissioning parents may be the genetic parents or donor eggs with the commissioning father's sperm may be used; in some cases, donor sperm is used.

A traditional surrogacy arrangement is when the surrogate's own egg is used; traditional surrogacy arrangements are much less common in contemporary contract pregnancies because of legal considerations, advances in ART, local and international regulations, laws regarding commercial surrogacy arrangements, and citizenship issues in global arrangements (Markens 2011; Rimm 2009). An altruistic surrogacy arrangement is one in which a surrogate is only reimbursed for expenses related to the pregnancy and birth of the child and is not a commercial arrangement; these may be either traditional or gestational surrogacy arrangements and are often among sisters, relatives, or close friends.
A global surrogacy arrangement is a contract pregnancy where the commissioning parents enter into a surrogacy arrangement across international borders, with a woman located in another country; these arrangements are commercial ones, in which there is a financial transaction and are almost always gestational surrogacy arrangements (Henaghan 2013). Increasingly, Western individuals or couples enter into surrogacy arrangements with women from lower-resource nations such as India or Thailand not only because surrogacy arrangements are less costly than elsewhere but also because the laws may be less restrictive than in their home countries, where commercial surrogacy may be either highly restricted or illegal (Hochschild 2009; Rimm 2009). In Canada, Israel, and the UK, for example, commercial surrogacy is banned, but an altruistic surrogate may be reimbursed for reasonable expenses related to the pregnancy (Henaghan 2013). In Germany, Italy, France, Japan, and China, surrogacy is banned outright (Henaghan 2013) and no form of surrogacy is permitted. In the USA, several states have liberal surrogacy laws, but US citizens still enter into global surrogacy arrangements with women from other nations, because of the prohibitive expense for surrogacy services in the USA (Henaghan 2013; Humbyrd 2009; Rimm 2009).

\section{Scope of the Problem}

Although global surrogacy arrangements have been portrayed as a win-win situation for both surrogate mothers and commissioning parents (Carney 2010; Hochschild 2009), human rights defenders and scholars in fields such as women's studies, bioethics, and law have become increasingly concerned about contemporary global surrogacy arrangements with some activists calling for a worldwide ban on surrogacy (Damelio and Sorensen 2008) and some opponents likening surrogacy to prostitution, slavery, and human-trafficking (Damelio and Sorensen 2008; Donchin 2010; Pande 2010b; Parker 2013). The major arguments against global surrogacy arrangements are in the following three broad categories: welfare, commodification, and exploitation (Humbyrd 2009); additionally legal conundrums due to lack of international regulation, can create situations in which parentlessness and/or statelessness arise (Henaghan 2013). These issues, along with concerns about oppression, that is "exploiting strangers, i.e., other societies and their people and resources" (Gil 1998, p. 21), require critical thinking about global surrogacy and controls necessary for social protection. Women in low-resource nations are particularly vulnerable and women in India are most frequently considered in the discourse about exploitation and human rights in global surrogacy (Pande 2009, 2010a, b; SAMA-Resource Group for Women and Health 2012). 


\section{A Look at Two Prominent but Contrasting Global Surrogacy Destinations: The USA and India}

\author{
Surrogacy in the USA
}

The USA, where surrogacy is widely practiced and has doubled since 2004 (Gugucheva 2010), is a fascinating case when examining surrogacy regulations and demands for surrogacy services by international commissioning parents and when also exploring questions related to exploitation in surrogacy arrangements. The USA is the only country in which it is both a common source and destination country for global surrogacy arrangements. US citizens increasingly seek surrogacy services outside of the USA mainly due to the exorbitant expense for surrogacy arrangements in the country (over US $\$ 100,000)$, while at the same time, the USA is a popular destination country for wealthier international commissioning parents seeking global surrogacy arrangements - particularly upper class Westerners from Canada, Europe, or Australia (Henaghan 2013) and also elite Chinese (Harney 2013).

The USA has the most liberal IVF, gamete donation, and surrogacy laws (in some states) of all the Western nations, while educated women (Berend 2012), some of which are reported to be military wives (Gugucheva 2010; Parker 2013) work as gestational surrogates to help other families while earning extra income.

In the USA, surrogacy regulations vary widely because they are governed by each one of the 50 states and the District of Columbia, with surrogacy being completely banned in Washington, DC and nearly unregulated in other states (Hinson and McBrien 2011). The early days of surrogacy and the infamous Baby $M$ case, in which a traditional surrogate refused to relinquish the child after giving birth and sought custody (Corea 1985), are in the past due to advances in ART; almost all contemporary surrogacy arrangements are gestational ones (Henaghan 2013). Written surrogacy laws on states' books can vary dramatically from actual surrogacy practices, regardless of written statutes in that state (Hinson and McBrien 2011). In states such as Arizona, Indiana, Michigan, and New York, statutes declare gestational surrogate contracts void, but surrogacy still continues in practice and most surrogacy arrangements are carried through successfully (Hinson and McBrien 2011). In states including California, Illinois, and Nevada, surrogacy is widely permitted and the states provide regulatory structure, so these states are considered to be the most surrogacy-friendly states, with California being a popular destination state for global surrogacy arrangements (Henaghan 2013). In states including Colorado, Georgia, and Oregon, there are no written statutes regarding surrogacy and there are no published cases to establish precedence in these states. However, pre-birth orders (PBOs) are routinely granted, which allow both commissioning parents to be named on the birth certificate, which makes surrogacy arrangements straightforward for all parties involved (Hinson and McBrien 2011).

\section{The USA as a Destination for Surrogacy Services}

The USA is a desirable destination country for upper middle class and wealthy international couples, because of the liberal surrogacy laws in some states, the high success rates of ART in the USA, and the generous citizenship laws, which grants US citizenship to any infant born on US soil, regardless of parentage (Henaghan 2013). Harney (2013) describes a significant increase in surrogacy agencies that cater to wealthy Chinese couples eager to enter into a surrogacy arrangement in the USA. The USA is considered to be a desirable destination for Chinese couples commissioning surrogacy arrangements because they can simultaneously circumvent China's restrictive one-child policy and obtain US citizenship for their children and possibly themselves later through their American-born offspring; any person born in the USA has the right to US citizenship upon birth. According to Harney (2013), surrogacy packages for Chinese customers cost between US\$120,000 and US\$200,000, with the surrogate receiving between US\$22,000 and US\$30,000 for carrying the pregnancy, making it an option available to only the most elite Chinese.

\section{A look at US Surrogates}

Critics of the US surrogacy market argue that, despite relative global wealth, US women working as gestational surrogates are exploited, because many, including military wives, are from families in the lowest income brackets and may be coerced to work as surrogates by a desire to supplement their family's income (Gugucheva 2010; Parker 2013). The sociodemographic dimensions of US surrogates are largely unknown, but surrogacy in the USA is sometimes portrayed as a market which preys on vulnerable women and is a form of severe reproductive injustice (Fixmer-Oraiz 2013; Parker 2013) in which surrogates are incapable of giving true informed consent (Gugucheva 2010). Damelio and Sorensen (2008) argue that US women who serve as surrogates are from the lowest income brackets and are open to abuse and exploitation because they do not likely have educational or financial resources.

Contrasting with this assertion, according to Stark (2012, p. 8), studies of US surrogates report that most surrogates "are white, married, Christian, and not especially poor. They do not feel exploited... Many report that they enjoy being pregnant. They are proud of their accomplishment, and glad that they could make such a difference in the lives of otherwise childless couples." Surrogate researchers have found that most US surrogates are lower middle class to middle class women who 
are married with families and are educated (Berend 2012; Stark 2012; Bromfield, A labor of love: A study of U.S. gestational surrogate bloggers, manuscript submitted for publication); US women report various reasons for entering into surrogacy arrangements with wanting to help others create a family (Berend 2012), having a sense of purpose (Ali 2008; Berend 2012), enjoyment of pregnancy (Stark 2012; Teman 2008), and feeling a sense of empowerment and self-worth (Ali 2008) being expressed as contributing factors. US surrogates tend to downplay the financial incentive while focusing on articulating altruistic motivations for being a surrogate (Ciccarelli and Beckman 2005; Hohman and Hagan 2001; Markens 2011). This is markedly different than in India, where surrogates report that they most often enter into surrogacy arrangements for the financial benefit (Carney 2010; Pande 2009; SAMA-Resource Group for Women and Health 2012).

\section{India as a Destination for Surrogacy Services}

While there is no attempt made in this analysis to compare surrogacy or surrogates in the USA and India due to the profound differences in economic, cultural, and social contexts between the two nations, it is worthwhile to discuss surrogacy in the USA contrasted with surrogacy in India, as they are both the most popular surrogacy destination countries worldwide (Markens 2011). India has a prevalent medical tourism market and surrogacy is one of the many services that can be purchased there. At this point in history, India is the most frequent source of global surrogacy services, other than the USA, and it is estimated that the industry is worth more over US\$400 million (Kohli 2011; Markens 2011). However, this is simply an estimate, because the largely unregulated nature of global surrogacy in India makes it impossible to know the exact transactions taking place in both economic terms as well as the actual number of resulting births (SAMA-Resource Group for Women and Health 2012). Further, the number of clinics engaged in the service is also only an estimate- 3,000 such clinics likely exist to serve upper class Indian couples as well as couples from countries such as Canada, the USA, Western European countries, and Australia (Hochschild 2009).

The lack of regulation and low cost for surrogacy services are the primary reasons for India as a popular choice for global surrogacy (SAMA-Resource Group for Women and Health 2012), although in 2013, India passed its first surrogacy regulation, which banned foreigners who were either single or gay from entering into surrogacy arrangements in India (The Telegraph 2013). The SAMA-Resource Group for Women and Health (2012) identifies that the laisse-faire approach to surrogacy in India, the low cost for surrogacy services compared to other countries, the shorter waiting time to be matched with a surrogate, the availability of women willing to be surrogates, and the possibility of close monitoring of these surrogates, as well as the modern medical infrastructure in India, are all important factors which contribute to India's desirability as a surrogacy destination.

When global surrogacy first began to rise and capture the attention of those seeking to build their families via alternative means, various media in the USA began to spotlight the practice in India. For example, the popular talk show host Oprah Winfrey called the practice a winwin scenario; with individuals and commissioning couples, as well as the gestational surrogates, respectively, "winning" from the arrangement (Carney 2010). Oprah's point was that people often facing the desperation of infertility pay a desperately poor woman-in need of a meaningful income-for a legitimate service. The benefits are different, but mutual from this perspective; a much wanted child is produced and a woman earns much needed income. As Oprah Winfrey is known to have a significant influence on market behaviors, inevitably this "win-win" framing of the issue promoted global surrogacy in India.

SAMA's analysis of the scenario underlying a woman's choice to participate as a surrogate considers dynamics of globalization and poverty and the positioning of a win-win scenario. The organization recognizes that in the context of globalization, Indian women are seeking new market opportunities and their sexual and reproductive services are included in the equation. Global surrogacy contracts are one of the resulting occupations. In this global transaction, opportunities for exploitation are of obvious concern, and in relatively recent research, surrogates in India have been interviewed for their perspectives on the practice. Extreme poverty, a dearth of work opportunities, and financial desperation are often cited as reasons why Indian women pursue surrogacy as a work option (Hochschild 2009; Pande 2009; SAMAResource Group for Women and Health 2012).

Pande (2009) interviewed surrogate women in India and found that the practice is considered "dirty work"- like that of a butcher or other relatively undesirable but needed occupation - and surrogates were willing to take on stigmatized work because the income was better than their other options for employment which is low wage and often dangerous. Such a cost-benefit approach to decision making is consistent with the social exchange theory in which a woman may weigh her options - working in a factory for very long hours and low wages or other more stigmatized but higher-paying work including dancing and bar-girl employment or sex work (Rotabi and Bromfield 2012).

Babies born in India do not have automatic rights to Indian citizenship and it is common practice in India to list the commissioning parents' names on a baby's birth certificate in a surrogacy arrangement, as the Indian birthmother is not considered legally to be the mother of the child in India. This has shown to have been problematic in countries where 
surrogacy is illegal and there have been cases of children, who were born of a surrogacy arrangement in India, who have been left stateless and the commissioning parents were unable to leave India with their child for some time (Henaghan 2013).

\section{Welfare and Global Surrogacy}

Fundamentally, the term "welfare" means well-being (Gamble 2012). The welfare argument against surrogacy arrangements makes the case that global surrogacy arrangements negatively impact the well-being of the surrogate and/or the resulting infant(s). Clearly, there is risk related to pregnancy and childbirth, and there is some level of discomfort, at the very least, involved in preparing a surrogate's body to receive embryos, often including daily injections of artificial hormones. In one known case, an Indian surrogate hemorrhaged and died several days after giving birth to a surrogate child for a Western couple (Carney 2010).

While the rate of caesarean sections (C-sections) in global surrogacy arrangements is not documented in terms of prevalence, they appear to be the norm in India (Carney 2010). Pregnancy has greater risk when Csections are the method of delivery. C-sections are more dangerous than vaginal births (Carney 2010), and any gestational carrier's future births also require appropriate medical care with this medical history especially if the woman has two or more C-sections (University of Maryland Medical Center, n.d.). Then as the woman goes on with her own family life, the issue becomes the fact remains that a poor woman cannot afford specialized medical attention that will monitor complications due to previous $\mathrm{C}$-sections. This is a critical issue that is likely underestimated (or even unknown) by gestational surrogates in their informed consent process. Unfortunately, there is no research literature on this long-term health consequence for women acting as surrogates in lowresource countries like India or Thailand.

An additional medical risk that is important to mention is that multiple births are more frequent in surrogacy arrangements due to the transfer of multiple embryos during the IVF process (SAMA-Resource Group for Women and Children 2012). The dangers of carrying and delivering multiple fetuses, including a higher risk for prematurity and low birth weight, are well documented (Koranantakul et al. 2007).

From a social-emotional welfare standpoint, another issue is the separation of these women from their families and communities during gestation, as it happens in some clinics in India that some surrogates live in a dormitory-style housing throughout their pregnancies (Carney 2010). This aspect of the practice appeals to those buying the service, because the clinic has control over environment, medical care, nutrition, and risky behaviors and can protect the surrogates from rumors and gossip in their home villages (Carney 2010; Hochschild 2009; Pande 2009). In some clinics, the surrogate's young children may stay with her in the clinic (Hochschild 2009); details of this practice and how common it actually is remains unknown, but for women that are separated from their family life, there is inevitably a consequence on intimate relationships. Obviously of concern is the mother-child relationship for those biological children who must be separated from their mothers for an extended period due to the surrogacy arrangement. While isolating women from their families and community is controversial, some surrogates have admitted that the housing, care, and nutrition that they receive while living at the clinic is superior to their day-to-day living conditions in impoverished communities while working in marginalized occupations (Hochschild 2009; Pande 2009). However, it must be noted that in many other marginalized occupations available to women, such as that of live-in housemaids, women workers must be separated from their own families for long periods of time, sometimes for many years at a time.

In relation to the welfare of the infant who results from a contract pregnancy, arguments such as the breaking of the natural mother-infant bond and the child's confusion related to his or her origins likens surrogacy to adoption. This positioning maintains that children born of surrogate arrangements may face similar struggles as adoptees who are disconnected from their birth families and various aspects of "identity, community, and belonging" (Cuthbert and Fronek 2014, p. 7), with an obvious difference being that children born of global surrogacy arrangements usually have a genetic connection and shared heritage with at least one of the commissioning parents and that parent's extended family, and also, that the arrangement was made between the commissioning couple and surrogate before the child's conception and birth.

Research evidence about identity formation and crisis is currently inadequate when it comes to global surrogacy arrangements. As such, it is impossible to make many assumptions about this issue and the welfare or wellbeing of the child. This is an area for further research, not unlike the plethora of similar research carried out investigating identity formation of intercountry adoptees (Rotabi and Bunkers 2011). However, in a longitudinal study on domestic surrogacy in the UK, researchers found that children born of surrogacy arrangements there remained positive about their birth and their surrogate mothers over a 10-year period (Jadva et al. 2012.

In cases where a child is stateless due to conflict in national surrogacy laws, it negatively impacts the child's welfare, although it appears that, to date, no child born of a surrogacy 
arrangement has remained stateless in perpetuity-because various nation courts recognize that the "best interest of the child" must prevail, and typically, humanitarian mechanisms of immigration law are used to remedy the situation.

\section{Commodification, Exploitation, Lack of Informed Consent, and Legal Issues in Global Surrogacy Arrangements}

\section{Commodification and Exploitation}

The commodification argument against surrogacy contends that paying surrogates equates to child-buying and reduces women to "wombs for hire." Some feminist scholars have likened surrogacy to prostitution and argue that, in contract pregnancies, a woman sells her womb and thus sells her body, relinquishing control over it (Damelio and Sorensen 2008). Others argue that surrogacy is "baby-selling," and this positioning emphasizes the power differential between the customer and the service provider, which is particularly pronounced with the vast majority of global surrogacy arrangements occurring in impoverished social environments, as discussed previously. This phenomenon has been considered by Pande (2009) and others, and the concept of exploitation is both explicit and implicit in the underlying argument (Karandikar, Gezinski, Carter, and Kalonga 2014). For example, a recent report by the Danish Council of Ethics (2013) on various transactions, including surrogacy, considers exploitation philosophically elaborating that "exploitation does not imply that the exploitee is necessarily worse off or harmed directly as a result of the transaction with the exploiter. On the contrary, it is consistent with the concept of exploitation that the exploited party is also afforded some advantage(s) by the transaction as compared with the original situation" (p. 28). In this treatment of the concept of exploitation, the conception of win-win is embedded while recognizing inequality, thereby creating an ethical dilemma that is ripe for critique.

One issue that was overlooked in Oprah's aforementioned showcase of the global surrogacy practice is the context of the medical industry and the vast sums of money earned by those who facilitate the process of human conception. Corea (1985), in her seminal work on the issue of selling surrogacy services and exploitation, calls the intermediaries in the process "surrogacy entrepreneurs" and she refers to the surrogate mothers themselves as "breeders." Corea's use of shock language is inevitably used to underscore the market and sales methods in surrogacy, including contracting human conception, gestation, and the infant delivery transaction. It should be noted that Corea's positioning is radical and her emotive use of words is indicative of an activist approach to surrogacy and an abolitionist stance grounded in exploitation of women by dominant structures, including the medical industry.

\section{Informed Consent}

A pragmatic position on global surrogacy recognizes that global surrogacy arrangements commonly involve commissioning parents from more wealthy countries who often seek surrogates from low-resource countries. As such, the chance of exploitation of surrogates is a serious and legitimate concern. The risk of exploitation is compounded given the multimillion dollar industry that has grown as a result of the supply and demand scenario that has emerged (Goodwin 2010). The power differential is such that informed consent is, at the least, a challenge, and it may be argued that many surrogates in countries like India or Thailand have limited options for relatively safe and sufficiently paid work available. Thus, the power of consent is not truly available to them, as there may not be other reasonable occupational alternatives with fair and equitable compensation.

Palattiyil (2010) points out that "Women who work as surrogates in this commercial reproductive industry appear to have little understanding of their rights, in terms of their own health and well-being" (p. 695). While there is no conclusive research evidence that women are ignorant to the risks of surrogacy, this concern is valid but it must be asserted carefully, as quickly drawn conclusions about "knowledge" can become quite paternalistic and dismissive about the abilities of women in poverty. However, social circumstances of extreme poverty combined with limited education make the Western orientation to the rights of free and informed consent impossible (Fasouliotis and Schenker 1999).

Turning back to Corea (1985), she challenges the structural realities of reproductive technologies and choices against the backdrop of gendered realities from her feminist perspective, questioning "What is the real meaning of 'consent'... in a society in which men as a social group control not just the choices open to women, but also women's motivation to choose?" (p. 3). Similar arguments are made by radical feminists who advocate for the abolition of legalized prostitution on a worldwide scale in their conflation of prostitution with human-trafficking (Bromfield and Capous-Desyllas 2012). Motivation to participate in surrogacy as an occupation, when framed by economic pressure and duress, indeed presents ethical dilemmas.

\section{Legal Issues Beyond Informed Consent}

Unfortunately, due to lack of international regulation or agreement regarding global surrogacy arrangements, a few children born from global surrogacy contracts have been subject to not 
having any legal parents and/or statelessness, which happened due to conflicting laws regarding parentage and citizenship. Conflict of law is an issue in global surrogacy cases and can cause statelessness for the child.

In the well-known Balaz case from 2008, commissioning parents from Germany-where surrogacy is bannedsought a global surrogacy arrangement in India. Embryos created from Mr. Balaz's sperm and donated eggs were transferred to an Indian surrogate and twin boys were born from the arrangement. Originally, the commissioning parents were both declared as the birth parents on the babies' birth certificates, as is usually the case with surrogacy arrangements in India. However, the German Embassy refused to recognize the birth certificates because surrogacy is banned in Germany (Henaghan 2013). The Indian government would not issue Indian passports for the babies because they were not considered to be Indian. After 2 years, the commissioning parents were finally able to travel from India to Germany with their babies after High Court intervention (Henaghan 2013) and sought adoption of their children in Germany.

For US citizens, the legal issues that plague commissioning parents from countries in which surrogacy is banned, such as Germany, do not complicate global surrogacy arrangements for most US citizens, as long as at least one of the US citizen parents is the genetic parent of the child; a certificate of birth abroad can be arranged through the US Embassy, as well as a US passport for the child. However, there has been at least one case in which a US citizen has had difficulty taking home her child born from a surrogacy arrangement in India (Umanadh 2012). In the Van Buren case, Perlinda Van Buren was delayed in being able to obtain documents for her child; the child was conceived using Van Buren's husband's sperm and an egg donor, so Ms. Van Buren had no genetic link to the child. Van Buren's husband was not a US citizen, but a citizen of Jamaica and was not able to travel to India due to an extreme fear of flying. The child had no genetic link to a US citizen parent. Furthermore, Jamaica did not have a consulate in India, which added to the complexities of this case (Umanadh 2012). Eventually, Van Buren was able to obtain the needed documents to leave India with her infant.

\section{Human Rights Instruments and Global Surrogacy Arrangements}

The absolute "right to parent" is not codified in any international agreements or human rights instruments. However, Struckenbruck (2013) points out that in the Universal Declaration of Human Rights (UDHR), adult men and women have the right to marry and find a family (Article 16.1), clarifying that it is not agreed upon if this means that an adult has a right to have a child regardless of that child's origin such as adoption or surrogacy arrangements. Now in contemporary society more than 50 years after the UDHR drafting, the manner in which a family life is formed creates new challenges in defining rights. While the term "family" is not explicitly defined in dominant rights instruments (Struckenbruck 2013), the Universal Declaration of Human Rights does identify that childhood is entitled to special care and assistance (Article 25.2) and motherhood is also to be protected (Article 25.2).

\section{Convention on the Rights of the Child and Surrogacy Arrangements}

The rights of children have been extensively identified in multiple human rights instruments, most notably the 1989 Convention on the Rights of the Child (CRC) which is the most universally agreed upon and ratified human rights treaty (Grandinier 2010). The CRC, founded on the principle of the best interests of the child, includes the right to identity, name, and family relationships (Article 6); the right for the child to know and be cared for by their parents (Article 7); and the right to not be separated from their parents without judicial review (Article 9). Also, the child has a right not to be stateless (Article 7) and their nationality is also to be guaranteed (Article 8). In the analysis of the practicality of the CRC and unique areas of consideration by Mama (2010), she points out that there is a special vulnerability of infants. When states protect children ages $0-1$, Mama asserts that they can "develop or refine policies to ensure that infants are taken care of well, safely, and without being exploited" (p. 187).

The exploitation of infants has not been explored in any detail, in the literature, as related to global surrogacy (e.g., infant distress), beyond the notion of baby-selling. This is an area in which there is a great lack of clarity as children born of global surrogacy typically have the benefit of excellent pre-natal and neo-natal care as their health is essentially a guarantee for this service sector. Furthermore, surrogacy arrangements cannot be considered to be baby-selling because a contract between the surrogate, the surrogate agency, and the commissioning parents existed before the infant was conceived; a service was contracted between the parties, not a child, although the birth of a healthy child is the desired outcome of the service. However, there is a large body of literature related to concerns about child sales into adoption-especially across international boundaries (Rotabi and Bunkers 2011). This form of child-trafficking - often with infants fetching the highest prices - is the focus of international private law, as will be presented later. 


\section{Convention on the Elimination of the Discrimination Against Women and Surrogacy Arrangements}

Exploitation and human rights are key concepts in the Convention on the Elimination of Discrimination against Women (CEDAW). CEDAW refers directly to rights of maternity in that "states are allowed to adopt special measures aimed at protecting maternity" (Article 4), and the intent of the international private law was the protection of rights such as maternity leave from work and other discrimination issues related to motherhood (Holtmaat and Naber 2011). There is no reference to rights of women engaged in the work that is the "occupation of maternity" in service to others. Surrogacy as it is practiced today, especially global surrogacy, was not even a concept when the law was passed in 1979.

However, CEDAW's main thrust is the recognition of women as a disadvantaged group and in the "human rights approach, discrimination of women is seen as an instance of their oppression... which is a mixture of exploitation, marginalization, powerlessness, cultural imperialism, and violence" as identified by Young (1990) (Holtmaat and Naber 2011, p. 24). These five violations of the human experience are major areas of human rights discourse, and they are largely captured in CEDAW's 30 articles focused on ending discrimination against women and many of the articles address women's equality in opportunities to work and civic participation. In the case of global surrogacy, a woman's right to choose one's work in addition to the right to participate in the development of regulatory approaches to fertility are consistent with CEDAW; global surrogacy presents critical challenges to the idea of "work" and control over reproduction.

When it comes to human transactions in the global economy, it suffices to say that all of the five areas of women's oppression relate directly to surrogates in low-resource countries. These dimensions of exploitation, marginalization, powerlessness, cultural imperialism, and violence (Young 1990) have an exponential effect when combined within the context of poverty. Further, these violations remind us that poor women are typically marginalized and experience powerlessness in their daily lives, including not having access to a living wage in low-resource nations. Cultural imperialism is a relevant argument because the extraction of a resource from one woman and her country for the benefit of another more powerful individual(s) and country is a worthy consideration in global surrogacy inequalities. Further, cultural realities of reproductive rights, health, and opportunity are all elements of the global surrogacy trade. Finally, violence against women is applicable - especially in low-resource countries where violence is often endemic and the social protection environment, including law enforcement, is best characterized by an absence of active legal and law enforcement protections consistent with impunity (Rotabi and Bromfield 2012).

\section{Vulnerability and Human Rights}

Vulnerability is always a core issue when securing rights. Focusing on protecting those who are the most vulnerable in the global surrogacy equation include the triangulated relations - surrogate, commissioning parent(s), and the resulting infant. The vulnerabilities of the surrogate and the resulting infant have been discussed in this paper, but it is necessary to mention the commissioning parent(s), who might be taken advantage of in the surrogacy arrangement and transactionthey have an emotional and financial vulnerability that is also at risk of exploitation and extortion by the intermediariescompounded by their probable genetic relationship to their infant; the vulnerabilities of commissioning parents along with their genetic bond to the infant should not be underestimated just because these individuals have financial resources (Haimowitz et al. 2010). However, the most vulnerable people must be afforded the greatest social protections and, in this case, commissioning parents are less vulnerable than the surrogate or the resulting infant.

There has been a resounding call for regulation of the surrogacy market in popular press as well as academic literature (Goodwin 2010). As agreement is sought in order to protect the vulnerable, the role of government verses private arrangements in the marketplace must be debated, and a consensus is necessary that considers at least two key sides of the dominant argument. As Gallager (2010) mentions, the private market place approach focuses on improving the functioning of the system. In counter, the classical liberal approach underscores values that focus on protecting those who are vulnerable from the marketplace while promoting equity.

In considering these two competing values orientations, international private law will now be discussed as the push to regulate the practice of global surrogacy presents itself.

\section{International Private Law: The "Hague Convention" Approach to Regulation}

The most common source of legal regulation, on a global basis, related to child and family matters is international private law that is in oversight by The Hague Permanent Bureau in The Hague, Netherlands. This institution develops international private law to harmonize legislation globally. For example, this has been the case for intercountry adoption (ICA) in which signatory states agree upon international standards of ICA.

The 1993 Hague Convention on Protection of Children and Co-operation in Respect to Intercountry Adoption (henceforth simply referred to as the HCIA) has been signed by well over 80 states and its central principle is the best interest of the child (Smolin 2010). In a cooperative manner, states agree upon core principles of ethical intercountry adoption transactions 
between two states with a prohibition on child-buying, as the sale and trafficking of children are crimes addressed by the HCIA. The abduction of a child into adoption is specifically addressed by the HCIA (Roby and Maskew 2012).

Due to problems in global surrogacy arrangements, The Hague Permanent Bureau has undertaken research to identify if there is a need for an international private law focused on global surrogacy (Hague Conference on International Private Law 2012). Results may be a pre-cursor to the next Hague Convention focused on global surrogacy in the near future. That being the case, policy planning must be careful to integrate the aforementioned concerns around surrogacy, as well as human rights guidance.

\section{Why Not Ban Global Surrogacy Arrangements?}

At this point in history, it is more pragmatic to meaningfully regulate global surrogacy. As surrogacy arrangements may open up some women to exploitation, it is critical to point out global surrogacy contracts are most likely no more exploitative than many other current and much lower-paying employment opportunities for the majority of women in low-resource nations. Furthermore, entering into a surrogacy agreement does not necessarily place the surrogate in a situation of exploitation, i.e., US citizen women who enter into global surrogacy arrangements with couples from other nations in which surrogacy is highly regulated or banned (Bromfield, A labor of love: A study of U.S. gestational surrogate bloggers, manuscript submitted for publication).

As Damelio and Sorensen (2008) argue, others have the autonomoy to accept jobs that compromise personal health. For example, coal miners know that coal mining is a dangerous occupation that may potentially shorten their lives, but they are still permitted to make the decision to be a coal miner (Damelio and Sorensen 2008). While this argument may be attacked as flawed as mining coal, as a much needed energy source, is far different from surrogacy as a service for sale, it is difficult to argue against a woman's right to choose her work and to be compensated fairly for that work. In some lowresource countries, surrogacy may be one of the better occupations available to a poor woman in terms of risk and rewards (Pande 2009).

Nussbaum (1999), on the consideration of "taking money for bodily services" points out that "It is widely believed... that taking money or entering into contracts in connection with the use of one's sexual and/or reproductive capacities is genuinely bad. Feminist arguments about prostitution, surrogate motherhood, and even marriage contracts standardly portray financial transactions in the area of female sexualty as demaning to women." (p. 277)

Nussbaum also considers the use one one's body across a range of professions:
"All of us, with the exception of the independently wealthy and the unemployed, take money for the use of our bodies. Professors, factory workers, lawyers, opera singers, prostitutes, doctors, legislators - we all do things with parts of our bodies for which we receive a wage in return. Some people get good wages and some do not; some have a relatively high degree of control over their working conditions and some have little control; some have many employment options and some have very few. And, some are socially stigmatized and some are not." (pp. 175-176)

The appropriate (moral vs. immoral) use of one's body is essential to the argument of surrogacy as a legitimate activity. Also, the concept of stigma has its place in considerations of global surrogacy and as identified previously, "dirty work" (Pande 2009). However, the banning of global surrogacy on the grounds that it is dangerous or stigmatizes women is questionable as many occupations would come under question, especially the work typically undertaken by people living in poverty in service to those who have more resources (e.g., house maids).

To illustrate the dangers of occupations readily available to improverished South Asian women, the 2013 garment factory collapse in Bangledesh is considered, which killed 1,129 people and left more than 2,500 people injured or maimed (Hussein 2013) including female workers, who worked long hours for little pay in a dangerous environment. While most acknowledge the need to improve the health and safety conditions for garmet workers, Western feminists and others are not generally heard advocating for a ban on garment factory work by women. In sum, the question of banning surrogacy is not pragmatic. Ultimately, solutions to poverty and ways of preventing exploitation are far more critical questions.

Fundamentally, the action more urgently needed is for the international community to assist in the alleviation poverty and to provide women with other opportunities, so that women will not feel pressured to choose surrogacy only for financial benefit. In support of this position, Crozier (2010) argues that the international community should not involve itself in restricting the participation of poor women in the reproductive tourism market for the sake of alleviating oppression and exploitation unless the women's participation in reproductive tourism arrangements, such as surrogacy, will deepen their oppression in a self-perpetuating manner. Crozier (2010) takes the stance that unless the international community is actively working on an agenda that will broaden other available options for poor women, it should hesitate to take action to limit poor women's access to higher-paying labor opportunities, such as surrogacy.

Humbyrd (2009, p. 112) argues that "the only valid objection to international surrogacy is that surrogate mothers may be exploited by being given too little compensation". She also maintains that global surrogacy arrangements are ethical if 
they follow fair trade principles. Further, her positioning is largely the same as those who argue for the legalization of prostitution - this freedom of choice position is articulated by Nussbaum (1999, p. 278) when she points out that "the most urgent issue raised by prostitution is that of employment opportunities for working women and their control over the conditions of their employment. The legalization of prostitution... is likely to make things a little better for women who have too few options to begin with".

Another seldom mentioned point in academic and policy discussions on surrogacy is that involuntary infertility is, in fact, a known harm both psychologically and sociologically (Corea 1985; Humbyrd 2009). Women who seek out surrogacy arrangements as a family-building option have most likely experienced years of infertility treatments and failed IVF cycles or have had uterine cancer, a hysterectomy, repeated miscarriages, or some other health problems that have driven them the extreme measure of contracting a pregnancy with a surrogate in order to have their child. Infertility message boards are littered with stories from women, who after a dozen or more failed IVF cycles of their own and often with mounting debt from infertility treatments, have finally resorted to surrogacy as a last attempt to have a child that is genetically connected to her and/or her partner. And for gay men who want to have a genetically related child, surrogacy is the most viable option (Stark 2012). However, as pointed out previously, there is no definitive human right to a child or to parent a child (Stark 2012) and, as such, making this argument in support of global surrogacy arrangements is problematic, especially in the face of concerns around exploitation and human rights. But hastily banning surrogacy outright and closing this option for family-building for couples who genuinely need a surrogate in order to have their own child is shortsighted when considering the entire equation.

\section{Pragmatic Policy Considerations and Recommendations}

This section begins with the term pragmatic, that is, a middle ground that does not take an abolitionist or proponent stance. Rather, it is clear that the practice is wanted by commissioning parents involved in the arrangement and countless women have now acted as global surrogates; research on these women indicates that they see the work as a viable occupation (Pande 2010a, b; Karandikar et al. 2014). These facts interface with a "baby market" in which many illegal and immoral activities are already taking place, including the intercountry adoption marketplace (Goodwin 2010; Gibbons and Rotabi 2012). Reasonable regulation is needed, integrating humanistic values. Underscored must be the idea of reasonable approaches to social protection as abolitionists will inevitably try to regulate the practice so strictly that global surrogacy arrangements could essentially become impossible to carry out.

The concept of dignity of work is central to a pragmatic position in which regulation of the occupation surrogacy is the intent, as well as the need for consideration of the best interest of the child. Critical and central to any ethical global surrogacy arrangement is free and informed consent in which due diligence is exercised in informing a surrogate of the risks. Saying that it is recognized that the concept of "free" may be lacking for people in extreme poverty. Also risks, as identified earlier, are medical as well as socio-emotional risks (SAMA-The Resource Group for Women and Children 2012). This includes the manner in which a mother receives follow-up care in the case of birth complications, with clear boundaries about the rights of and limitations to future care within the surrogacy clinic as well as elsewhere in the community. As such, some pragmatic policy recommendations are outlined:

(1) Informed consent guidelines must be developed that not only meet Western societies definition of the process but also are culturally relevant to women in low-resource countries where there are likely challenges related to education and other factors in understanding the risks of surrogacy. Consent must be secured with relevant language, both verbal and written, and with an impartial counselor facilitating the process. Critical to developing a fair consent process in spirit, as well as practically, is the inclusion of the context of poverty and the desperate circumstances that create the opportunity for surrogacy and the global exploitation of poverty and the understanding that a woman may be "pressured" into a surrogacy arrangement by a husband or other family member.

(2) Financial transactions, mainly the compensation for surrogates, must be managed in a manner that is both transparent, as well as safeguarded, including how financial incentives are used in the consent process. Further, in terms of transparency, a surrogacy clinic should be required to report its transactions to a national oversight body in that country with clear documentation of the amount of money paid to each surrogate per pregnancy. Surrogates should be paid a standardized, fair, and competitive wage in that country for a surrogate pregnancy, regardless of personal circumstances of the surrogate and/or the commissioning parent(s). Also, it is important that these transactions are safeguarded so that the women themselves have autonomy over the money in a way that lessens the likelihood of a third party exploiting the woman (e.g., a family member forcing the surrogacy arrangement for their own financial benefit). This means lowering the risk of the woman being coerced into the practice by an individual who will take advantage of her earnings just as a pimp controls and benefits from a sex worker's occupation and income. 
(3) In order to insure informed consent and transparent financial transactions, surrogacy clinics and living conditions of surrogates must be monitored in a manner that is consistent with accreditation of medical facilities. A heavy emphasis on the rights of the surrogate and the unborn child must inform the process of developing an accreditation system that holds the surrogacy entrepreneurs accountable to fair and safe work conditions before, during, and for some agreed upon period after the pregnancy and delivery.

(4) Health coverage for the surrogate that will pay for her health care expenses for a specified time period during and after the surrogacy arrangement. This will insure that the woman will receive proper medical care for a relevant period, most especially after the pregnancy and delivery.

Other pragmatic considerations include vulnerability of all in the surrogacy triad. While the best interests of the child is an important principle in international private law thus far as related to child rights, an expanded conception of rights must include all three positions of vulnerability in the global surrogacy triad (surrogate, child, and commissioning parent or parents) with a strong emphasis on vulnerable women and the need to protect them without being paternalistic. Such a position recognizes their need for viable work with a respectable income.

An expanded conception that is more collectivist and reaches beyond the child may be called in the best interests of family life in which both the surrogate, as well as the commissioning parent(s) are recognized, which allows for all of the various grey areas of parental rights to be clarified in this new and technologically advanced human transaction of reproduction and family formation. Such an approach is immensely complex and has been debated fiercely since the Baby $M$ case; disagreement about parental rights strikes at the heart of the surrogacy debates. It is further recommended that:

(1) Any international private law that arises from reform initiatives incorporate clearly defined concepts of family and parentage, while providing guidance for how to determine the ultimate responsibility for the child based on "best interests," in general, and with the child's future to be of paramount importance.

(2) The best interests of the child remains an important principle when one makes this consideration of a child's future, especially as related to citizenship and the right to be parented or raised in a family environment, in cases that a commissioning family rejects the child due to some characteristic that is deemed undesirable or there is another unforeseen event, such as the death of the commissioning parents; the family environment may include the commissioning parents' extended family. To ignore this principle, as set forth in the CRC and also codified in the HCIA, is to ignore the reality that a small but important percentage of cases will fall into a dangerous social circumstance in which a child may not have rights of citizenship and/or become a social orphan. As such, the child rights must be thoroughly treated in future law.

(3) That the vulnerabilities of commissioning families are acknowledged and that commissioning parents are protected from extortion and blackmail by surrogacy clinics through government oversight, transparency, and accountability. Surrogacy clinics should present a detailed and outlined contract to the commissioning parents, indicating total fees for the surrogacy arrangement, among other important points. Clinics should avoid entering into global surrogacy arrangements with commissioning parents who will not be able to legally return to their country with their child. Commissioning parents should have the right to meet and have an ongoing relationship with the surrogate during the pregnancy.

Finally, monitoring activities of surrogacy clinics and even the number of children born to surrogacy arrangements inevitably raises privacy issues; however, developing a datatracking system that protects privacy while documenting numbers of global surrogacy arrangements is an important consideration in regulation of global surrogacy.

\section{Research and Practice Priorities}

Rigorous empirical research is needed on the long-term impact of global surrogacy arrangements on those involved in the surrogacy triad: surrogates, commissioning parents, and children. In particular, research that is objective and unbiased by the moral panic (Berend 2012) and cultural anxieties around surrogacy (Teman 2008) is essential. Greater empirical clarity is needed to aid in the process of defining social policies from a true social justice and human rights perspective (Rotabi et al., International private law to regulate commercial global surrogacy practices: Just what are social work's practical policy recommendations?, under review).

While social workers have an institutionalized role in adoption standards and procedures, the profession's role in global surrogacy is unclear. The social work profession has not been a core service provider in global surrogacy practices; this presents obvious challenges, including the profession's assertion of relevance in the surrogacy policy making process (Rotabi et al., International private law to regulate commercial global surrogacy practices: Just what are social work's practical policy recommendations?, under review). While the profession's capacities may be clear to social workers, in both clinical and macro-level social work, and some social workers do practice as infertility counselors and educators 
(Rotabi et al., International private law to regulate commercial global surrogacy practices: Just what are social work's practical policy recommendations?, under review), the profession's value is often overlooked by other disciplines involved in drafting laws (Fronek and Crawshaw 2014). Social workers should move beyond position statements (International Federation of Social Workers 2013) on global surrogacy toward a consideration of the finer points of regulation - including a consideration of the role of social workers as professionals in the process (Rotabi et al. 2014).

\section{Conclusion}

What has been presented here is remarkably complex and the ethical dimensions create difficult terrain to navigate. The authors have some disagreement with each other about the various aspects of global surrogacy and this underscores the complicated nature of the practice, the highly emotional dimensions of the arguments for and against the practice, and the problems associated with a largely unregulated industry which is raging away in low-resource countries, where poor women face exploitation daily. As presented, there is concern about the many aspects of exploitation and human rights that may be existent in some global surrogacy arrangements and these are grounds for mutual agreement. Furthermore, there is no assertion made for the rights of a relatively privileged individual or couple consumer over the rights of a vulnerable woman in a low-resource country or anywhere in the world. While international regulation of global surrogacy is needed, standards of practice should be developed with input from all involved in the transaction, and most especially the surrogates themselves.

\section{References}

Ali, L. (2008). The curious lives of surrogates. Newsweek. Retrieved June 25, 2014, from http://www.newsweek.com/curious-livessurrogates-84469.

Berend, Z. (2012). The romance of surrogacy. Sociological Forum, 27(4), 913-936.

Bromfield, N., \& Capous-Desyllas, M. (2012). Underlying motives, moral agendas and unlikely partnerships: The formulation of the U.S. trafficking victims protection act through the data and voices of key policy players. Advances in Social Work, 13(2), 243-261.

Carney, S. (2010). Cash on delivery: Gestational dormitories. Routine Csections. Quintuple embryo implants. Brave new world? Nope surrogacy tourism. Mother Jones, pp. 69-73. http://www. motherjones.com/politics/2010/02/surrogacy-tourism-india-naynapatel.

Ciccarelli, J., \& Beckman, L. (2005). Navigating rough waters: An overview of psychological aspects of surrogacy. Journal of Social Issues, 61(1), 21-43.
Corea, G. (1985). The mother machine: Reproductive technologies from artificial insemination to artificial wombs. New York: Harper \& Row Publishers.

Crozier, G. (2010). Protecting cross-border providers of ova and surrogacy services? Global Social Policy, 10(3), 299-303.

Cuthbert, D., \& Fronek, P. (2014). Perfecting adoption? Reflections on the rise of commerical offshore surrogacy and family formation in Australia. In D. Higgins (Ed.), Children and families in Australia: Selected policy, legal and practical issues. Melbourne: Australia: Australian Institute of Family Studies.

Damelio, J., \& Sorensen, K. (2008). Enhancing autonomy in paid surrogacy. Bioethics, 22(5), 269-277.

Danish Council of Ethics. (2013). International trade in human eggs, surrogacy and organs. Copenhagen: Danish Council of Ethics.

Donchin, A. (2010). Reproductive tourism and the quest for global gender justice. Bioethics, 27(7), 323-332. doi:10.1111/j.14678519.2010.01833.x.

Fasouliotis, S., \& Schenker, J. (1999). Social aspects of assited reproduction. Human Reproduction Update, 5(1), 26-39.

Fixmer-Oraiz, N. (2013). Speaking of solidarity. Frontiers, 34(3), 126-163.

Fronek, P., \& Crawshaw, M. (2014). The "New Family" as an emerging norm: A commentary on the position of social work in assisted reproduction. British Journal of Social Work. doi:10.1093/bjsw/ bct198.

Gallager, M. (2010). Why do parents have rights? The problem of kinship in liberal thought. In Baby markets: Money and the new politics of creating families (pp. 164-176). New York: Cambridge University Press.

Gamble, D. N. (2012). Well-being in a globalized world: Does social work know how to make it happen? Journal of Social Work Education, 48(4), 669-689.

Gibbons, J. L., \& Rotabi, K. S. (Eds.). (2012). Intercountry adoption: Policies, practices, and outcomes. Surrey: Ashgate Press.

Gil, D. G. (1998). Confronting injustice and oppression: Concepts and strategies for social workers. New York: Columbia University Press.

Goodwin, M. B. (2010). Baby markets: Money and the new politics of creating families. New York: Cambridge University Press.

Grandinier, M. (2010). Introduction: Why should the United States ratify the convention on the rights of the child? Child Welfare, 89(5), 7-13.

Gugucheva, M. (2010). Surrogacy in America. Council for Responsible Genetics. http://www.councilforresponsiblegenetics.org/ pagedocuments/kaevej0a1m.pdf.

Hague Conference on International Private Law. (2012). A preliminary report on the issues arising from international surrogacy arrangements. The Hague, Netherlands: Hague Permanent Bureau.

Haimowitz, R., Vaishali, S. (Writers), Haimowitz, R., \& Vaishali, S. (Directors). (2010). Made in India [Motion Picture]. USA. http:// www.madeinindiamovie.com/.

Harney, A. (2013). Why wealthy Chinese are seeking U.S. surrogates. Reuters. http://www.reuters.com/article/2013/09/22/us-chinasurrogates-idUSBRE98L0JD20130922.

Henaghan, M. (2013). International surrogacy trends: How family law is coping. Australian Journal of Adoption, 7(3). Retrieved from http:// www.nla.gov.au/openpublish/index.php/aja/article/view/3188.

Hinson, D., \& McBrien, M. (2011). Surrogacy across America: Both the law and the practice. Family Advocate, 34(2), 32-36.

Hochschild, A. (2009). Childbirth at the global crossroads. The American prospect. Retrieved from http://prospect.org/article/childbirthglobal-crossroads- 0 .

Hohman, M., \& Hagan, C. (2001). Satisfaction with surrogate mothering: A relational model. Journal of Human Behavior in the Social Environment, 4(1), 61-84.

Holtmaat, R., \& Naber, J. (2011). Women's human rights and culture. Cambridge, UK: Intersentia. 
Humbyrd, C. (2009). Fair trade international surrogacy. Developing World Bioethics, 9(3), 111-118.

Hussein, S. (2013). Six months after Bangladeshi factory collapse, workers remain in peril. cnn.com. http://edition.cnn.com/2013/10/24/opinion/ bangladesh-garment-workers/. Accessed January 31, 2014.

International Federation of Social Workers [IFSW]. (2013, December 4). Taking the IFSW policy on international surrogacy forward - seeking social worker's views. http://ifsw.org/news/the-private-internationallaw-issues-surrounding-the-status-of-children-including-issuesarising-from-international-surrogacy-arrangements/.

Jadva, V., Blake, L., Casey, P., \& Golombok, S. (2012). Surrogacy families 10 years on: Relationship wiht the surrogate, decisions over disclosure and children's understanding of their surrogacy origins. Human Reproduction, 27(10), 3008-3014.

Karandikar, S., Gezinski, L. B., Carter, J. R., \& Kaloga, M. (2014). Economic necessity or noble cause? A qualitative study exploring motivations for gestational surrogacy in Gujarat, India. Affilia, 29(2), 224-236. doi:10. $1177 / 0886109913516455$.

Kohli, N. (2011). Mom's Market. Hindustan Times. Delhi: Hindustan Times.

Koranantakul, O., Suwanrath, C., Suntharasaj, T., Getpook, C., \& Leetanaporn, R. (2007). Outcomes of multifetal pregnancies. Journal of Obstetric Gynaecological Research, 33(1), 49-55.

Mama, R. (2010). Needs, rights, and hte human family: The practicality of the convention on the rights of the child. Child Welfare, 89(5), 177-189.

Markens, S. (2011). Interrogating naratives: About the global surrogacy market. The Scholar and Feminist Online, 9, 1-2.

Nussbaum, M. C. (1999). Sex and social justice. New York: Oxford University Press.

Palattiyil, G. B. (2010). Globalization and cross-border reproductive services: Ethical implications of surrogacy in India for social work. International Social Work, 53(5), 686-700.

Pande, A. (2009). 'Not an angel' not 'a whore': Surrogates as 'dirty workers' in India. Indian Journal of Gender Studies, 16, 141-173.

Pande, A. (2010a). At least I am not sleeping with anyone: Resisting the stigma of commercial surrogacy in India. Feminist Studies, 36(2), 292.

Pande, A. (2010b). Surrogacy in India: Manufacturing a perfect motherworker. Signs, 35(4), 968-992.

Parker, K. (2013, May 25). Surrogacy exposed. The Washington Post. http:/www.washingtonpost.com/opinions/kathleen-parker-theexploitation-of-surrogate-mothers/2013/05/24/90bc159e-c4b011e2-8c3b-0b5e9247e8ca_story.html.
Rimm, J. (2009). Booming baby business: Regulating commercial surrogacy in India. University of Pennsylvania Journal of International Law, 30(4), 1429.

Roby, J. L., \& Maskew, T. (2012). Human rights considerations in intercountry adoption: The children and families of Cambodia and Marshall Islands. In J. L. Gibbons \& K. S. Rotabi (Eds.), Intercountry adoption: Policies, practices and outcomes (pp. 5566). Surrey: Ashgate Press.

Rotabi, K., \& Bromfield, N. F. (2012). Intercountry adoption declines lead to new practices of global surrogacy in Guatemala: Global human rights concerns in the context of violence and the era of advanced fertility technology. Affilia, 27(2), 129-141.

Rotabi, K. S., \& Bunkers, K. M. (2011). In the era of reform: Reviewing social work's contributions to the intercountry adoption literature. Sage Open. doi:10.1177/2158244011428160.

SAMA-Resource Group for Women and Health. (2012). Birthing a market: A study on commercial surrogacy. Retrieved from SAMA women's health. http://www.samawomenshealth.org/downloads/ Birthing\%20A\%20Market.pdf. Accessed January 26, 2014.

Smolin, D. N. (2010). Child laundering and the Hague convention on intercountry adoption: The future and past of intercountry adoption. Louisville Law Review, 48, 441-498.

Stark, B. (2012). Transnational surrogacy and international human rights law. ILSA Journal of International \& Comparative Law, 18(2). http://ssrn.corn/abstract $=2118077$.

Struckenbruck, D. (2013). The rights of the child deprived of a family environment: Domestic adoption of children in Kenya. Institut Universiataere Kurt Bosch-University of. Fribourg: Institut Universiataere Kurt Bosch-University of Fribourg.

Teman, E. (2008). The social construction of surrogacy research: An anthropological critique of the psychosocial scholarship on surrogate motherhood. Social Science \& Medicine, 67, 1104-1112.

The Telegraph. $(2013,18)$. India bans gay foreign couples from surrogacy. The Telegraph. http://www.telegraph.co.uk/news/worldnews/ asia/india/9811222/India-bans-gay-foreign-couples-fromsurrogacy.html. Accessed January 31, 2014.

Umanadh, J. (2012). MEA may allow American woman to take home surroate child. Deccan Herald. http://www.deccanherald.com/ content/222594/mea-may-allow-american-woman.html.

Young, I. M. (1990). Justice and politics of difference. Princeton: Princeton University Press. 